\title{
HISTÓRIA E ESTUDOS SOCIAIS: NOVAS ABORDAGENS
}

SANTOS, Beatriz Boclin Marques dos. O currículo da disciplina escolar História no Colégio Pedro II - a década de 1970 - entre a tradição acadêmica e a tradição pedagógica: a História e os Estudos Sociais. Rio de Janeiro: Mauad X/FAPERJ, 2011.

Resenhado por:

Thiago Rodrigues Nascimento ${ }^{1}$

O currículo da disciplina escolar História no Colégio Pedro II - a década de 1970 - Entre a tradição acadêmica e a tradição pedagógica: a História e os Estudos Sociais (2011), de autoria da historiadora fluminense Beatriz Boclin Marques dos Santos, tem sua origem em tese de doutorado defendida, sob orientação de Ana Maria Monteiro, no Programa de Pós-graduação em Educação da Universidade Federal do Rio de Janeiro em 2009. O trabalho se insere no conjunto crescente de pesquisas sobre a história de constituição das disciplinas escolares e aborda um tema pouco explorado pelos historiadores, a institucionalização do ensino da disciplina escolar Estudos Sociais ao longo dos anos de 1960 e 1970 e como os professores, neste caso os vinculados ao Colégio Pedro II, dialogaram com este contexto.

O ensino de Estudos Sociais no Brasil está fortemente associado à política educacional implementada pelo Conselho Federal de Educação (CFE) durante os anos em que o país viveu sob o Regime Militar (1964-1985). Neste sentido, muitos professores de História e historiadores, sobretudo, os que atuaram na luta contra os Estudos Sociais e as licenciaturas curtas no decorrer dos anos de 1970 e 1980, tende a associar os Estudos Sociais ao período autoritário. No entanto, as discussões em torno do tema se remetem, no Brasil, aos anos de 1920 no bojo de introdução do movimento da Escola Nova no país. Recentemente alguns estudos têm revisitado este objeto. Antonia Terra Fernandes (2008) analisa a introdução dos Estudos Sociais no país durante as primeiras décadas do século XX, destacando a atuação de Carlos Delgado de Carvalho - autor de um Programa de Ciências Sociais, publicado em 1934 sob os auspícios do Departamento de Educação do Distrito Federal dirigido por Anísio Teixeira. Maria do Carmo Martins (2000) investiga em importante tese de doutorado, dentre outros aspectos, as concepções pedagógicas que guiaram os Conselheiros do CFE na implantação e defesa de inclusão dos Estudos Sociais nos currículos escolares durante os anos de 1970 e 1980. Thiago Rodrigues Nascimento (2012) se propõe a traçar uma história das discussões sobre a formação do professor de Estudos Sociais no Brasil a partir de 1930, enfocando a legislação sobre o assunto aprovada pelo CFE entre as décadas de 1960 e 1970.

Tais trabalhos retomam um velho objeto e recuperam a historicidade dos Estudos Sociais na escola brasileira. Santos (2011) apresenta uma nova abordagem historiográfica acerca da disciplina escolar Estudos Sociais nas décadas de 1960 e 1970. Isso significa reconstruir a história desta disciplina escolar em sua trajetória de divulgação e institucionalização no Brasil a partir dos anos de 1930. O objetivo central da pesquisa é a análise da "história do currículo da disciplina escolar História no Colégio Pedro II". O foco reside na década de 1970 quando, a partir da Lei $\mathrm{n}^{\circ} 5.692$ de 11 de agosto de 1971, os Estudos Sociais substituíram a História e a Geografia no currículo do ensino de $1^{\circ}$ grau. Apesar de ser uma tradicional instituição federal, o Colégio Pedro II não seguiu as determinações contidas na Lei e manteve a disciplina escolar História. Esta não adoção dos Estudos Sociais e os fatores que levaram a recusa de implantação no currículo escolar desta nova disciplina configuram como uma das principais questões levantadas por Santos 
(2011). Utilizando como referencial teórico os trabalhos do pesquisador inglês Ivor Goodson e manuseando um amplo leque de fontes, Atas das reuniões da Congregação, Conselho Departamental e Departamento de História do Colégio Pedro II, livros didáticos escritos por professores catedráticos da Instituição e entrevistas temáticas com ex-docentes e alunos, a autora traça uma história da "dinâmica de desenvolvimento curricular" do Colégio Pedro II.

No Capítulo 1, o objetivo é analisar As contribuições de Ivor Goodson para as pesquisas sócio-históricas do currículo. A utilização de tal referencial teórico permite a autora a compreensão acerca dos elementos componentes do currículo e sua "fabricação" enquanto "artefato social resultado de uma dinâmica social marcada pelas lutas entre diferentes concepções sociais" (p. 29). Portanto, sendo a confecção do currículo um processo social, ele não é algo fixo, mas está em constante fluxo e transformação. Sujeito às mudanças e flutuações, o que significa que em determinados contextos históricos "um determinado conhecimento predomine sobre outros, que foram rejeitados" (p. 29).

No Capítulo 2, o foco reside na compreensão acerca da constituição e as características do currículo da disciplina escolar História no Colégio Pedro II durante os anos do Império do Brasil (1837-1889). Assim, a autora inicia um percurso de análise sobre a introdução do ensino de História no país a partir da criação do Colégio Pedro II e o papel deste ensino na construção do conceito de nação. Durante o século XIX, sobretudo, a partir de finais do Período Regencial (1831-1940), a disciplina História teve um papel importante: "o de contribuir para forjar a nacionalidade brasileira" (p. 51). Para a autora, se o Instituto Histórico e Geográfico Brasileiro era o lugar da produção histórica, o Colégio Pedro II era o lugar da produção didática. Os seus primeiros professores catedráticos foram responsáveis pela confecção de manuais e compêndios didáticos. Esta característica do professorado do Colégio marcaria uma de suas grandes peculiaridades, o envolvimento destes tanto com a História acadêmica quanto com a ensinada (p. 87).

No Capítulo 3, aborda o currículo de História durante o período republicano entre 1889, ano da Proclamação da República, e 1970. Durante este contexto se configuraram diferentes reformas educacionais e programas de ensino. Grandes nomes, como João Ribeiro e Jonathas Serrano, autores de livros didáticos de História, atuaram como professores catedráticos do Colégio Pedro II. A autora analisa os programas de História em três momentos, primeiros anos da República, anos de 1930 e 1940 - período das Reformas Francisco Campos e Gustavo Capanema (1930-1945) - e as décadas de 1950 e 1960 e as formas como os professores do Colégio se apropriaram destes programas e contribuíram para a sua construção.

A trajetória dos Estudos Sociais enquanto disciplina escolar no Brasil é o objeto do Capítulo 4. Para o desenvolvimento desta história a pesquisadora toma como base a periodização traçada por Elza Nadai (1988), em texto onde esta busca recuperar a historicidade dos Estudos Sociais na escola brasileira. A análise do que foram os Estudos Sociais após o evento político de 1964 e as inovações que as legislações educacionais, produzidas entre os anos de 1970 e de 1980, trouxeram para as discussões em torno da incorporação desta disciplina nos currículos escolares não é possível sem um retorno necessário as primeiras décadas do século XX quando foram iniciados os primeiros debates sobre a temática. Assim, a autora recupera a influência da filosofia educacional formulada pelo norte-americano John Dewey e do movimento da Escola Nova sobre a introdução dos Estudos Sociais no Brasil dos anos de 1930. Nas décadas de 1950 e 1960 o debate foi guiado pelo professor Carlos Delgado de Carvalho e suas produções. As reformas educacionais processadas durante a década de 1970 se apropriaram desta discussão e concepção de Estudos Sociais. Para Santos (2011, p. 197), “a análise do Parecer 853/71 e o 
depoimento da Conselheira Terezinha Saraiva nos permitem concluir que muitas concepções presentes na Lei $\mathbf{n}^{\mathbf{0}} \mathbf{5 . 6 9 2 / 7 1}$ foram defendidos ao longo da década de 1960 e consolidados em 1971"1. Um dos méritos do capítulo é justamente demonstrar que a inclusão dos Estudos Sociais nos currículos escolares dos anos de 1970 fez parte de um projeto educacional desenvolvido pelo CFE e que vinha em marcha neste Conselho desde antes do golpe civil-militar de 1964.

No último capítulo do livro, a autora analisa como a comunidade disciplinar de História do Colégio Pedro II interagiu ou não com a reforma educacional promovida pela Lei 5.692/71. Santos (2011, p. 235), “entende que a matéria Estudos Sociais não foi implantada no Colégio Pedro II, porque representava uma mudança curricular que, embora afetasse a forma organizacional, não se fazia acompanhar pelos padrões institucionais". A disciplina escolar História esteve, durante o período analisado pela pesquisadora, intimamente ligado à tradição do Colégio Pedro II, uma tradição que ajudou a construir. Para Santos (2011, p. 236):

A História representava uma disciplina fundamental no currículo, marcada pela tradição dos professores catedráticos, autores de livros didáticos que ocupavam posições de poder dentro e fora do Colégio, com projeção pessoal, respeitados seja por sua atuação no ensino secundário, seja no ensino superior.

Neste sentido, a substituição da História e da Geografia pelos Estudos Sociais representou um conflito entre a "tradição acadêmica" e tradição pedagógica. O currículo do Colégio Pedro II era tradicional, baseado na preparação dos jovens que ambicionavam ingressar no ensino superior. "O status da disciplina História esteve relacionado à referência acadêmica". Já o ensino de Estudos Sociais tinha outra pretensão, "a educação centrada na criança e sua inserção social". Os Estudos Sociais propostos pelo Conselho Federal de Educação durante a década de 1970, ao propor o ensino em grandes áreas do conhecimento, pretendeu romper a estrutura disciplinar que caracterizava a escola brasileira até então. Assim, concluindo, Santos (2011, p. 232), aponta que "os Estudos Sociais não só não entraram no currículo do Colégio Pedro II, como também não houve interferência do governo militar nas questões pedagógicas do Colégio". Isso se explica pelo "peso da tradição da disciplina História" na Instituição e pela atuação dos seus professores em diferentes ambientes políticos e educacionais.

Apresentamos alguns dos pontos abordados ao longo de seu livro. Não tivemos a pretensão de esgotá-los, mas destacar para os leitores a importância desta obra para o campo de pesquisa do ensino de História. Tencionamos levar o leitor a curiosidade e interesse pelo tema. Anos se passaram desde que os Estudos Sociais se tornaram obrigatórios durante o Regime Militar e, ainda hoje, existe certa resistência dos pesquisadores quando o assunto é esta disciplina escolar. O estudo desenvolvido por Beatriz Boclin Marques dos Santos contribui para a desmistificação de um tema pouco abordado pelos historiadores. Já era hora de enfrentarmos o que Déa Fenelon denominou nos anos de 1980 como "a questão dos Estudos Sociais". Um dos grandes méritos de Santos (2011) é analisar esta "questão" em profundidade e ao longo de diferentes períodos, para além dos anos em que o país viveu sob o regime pós-1964. Trata-se de livro necessário à biblioteca daqueles que se dedicam a analisar a história do ensino de História e a história da educação brasileira recente. 
Referências

FERNANDES, Antonia Terra. Estudos Sociais no contexto da história brasileira nas primeiras décadas do século XX. Anais XIX Encontro Regional de História: Poder, Violência e Exclusão. ANPUH/SP. 2008 Set. 8-12. São Paulo: ANPUH/SP, 2008. Disponível em:

$<$ http://www.anpuhsp.org.br/sp/downloads/CD\%20XIX/PDF/Autores\%20e\%20Artigos/An tonia\%20Terra\%20de\%20Calazans\%20Fernandes.pdf>. Acesso em: 21 maio de 2012.

MARTINS, Maria do Carmo. A História prescrita e disciplinada nos currículos escolares? Quem legitima estes saberes. 2000. 263 f. Tese (Doutorado em Educação) - Faculdade de Educação, Universidade Estadual de Campinas, UNICAMP, 2000.

NASCIMENTO, Thiago Rodrigues. Licenciatura curta em Estudos Sociais no Brasil: sua trajetória na Faculdade de Formação de Professores de São Gonçalo/RJ (1973-1987). 2012. 236 f. Dissertação (Mestrado em História Social) - Faculdade de Formação de Professores, Universidade do Estado do Rio de Janeiro, 2012. 